\title{
Sex steroid action in adolescence: too much, too little; too early, too late
}

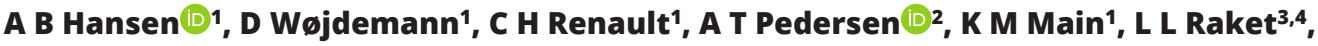 \\ R B Jensen ${ }^{1}$ and $A$ Juul 1 1 \\ 1Department of Growth and Reproduction, ${ }^{2}$ Department of Gynecology and Fertility Clinic, Rigshospitalet, University \\ of Copenhagen, Copenhagen, Denmark, ${ }^{3} \mathrm{H}$. Lundbeck A/S, Valby, Hovedstaden, Denmark, and ${ }^{4} \mathrm{Clinical}$ Memory \\ Research Unit, Department of Clinical Sciences, Lund University, Lund, Sweden
}

Correspondence

should be addressed

to A Juul

Email

anders.juul@regionh.dk

\begin{abstract}
This review aims to cover the subject of sex steroid action in adolescence. It will include situations with too little sex steroid action, as seen in for example, Turners syndrome and androgen insensitivity issues, too much sex steroid action as seen in adolescent PCOS, CAH and gynecomastia, too late sex steroid action as seen in constitutional delay of growth and puberty and too early sex steroid action as seen in precocious puberty. This review will cover the etiology, the signs and symptoms which the clinician should be attentive to, important differential diagnoses to know and be able to distinguish, long-term health and social consequences of these hormonal disorders and the course of action with regards to medical treatment in the pediatric endocrinological department and for the general practitioner. This review also covers situations with exogenous sex steroid application for therapeutic purposes in the adolescent and young adult. This includes gender-affirming therapy in the transgender child and hormone treatment of tall statured children. It gives some background information of the cause of treatment, the patient's motivation for medicating (or self-medicating), long-term consequences of exogenous sex steroid treatment and clinical outcome of this treatment.
\end{abstract}

\section{Introduction}

In females, the production of estradiol (E2) stimulates estrogen-receptors (ER) in estrogen-sensitive tissues and organs like breast, uterus, fat and bone. In males the

\section{Invited Author's profile}

Anders Juul is a pediatric endocrinologist and EAA certified andrologist. He is the head of the department of growth and reproduction at Rigs hospitalet, and clinical professor at the University of Copenhagen, Denmark. His research has focused on puberty and growth and their disorders, including the role of IGF-I and its binding proteins in the diagnosis and monitoring of GH deficiency. He initiated the North European Small for Gestational Age Study (NESGAS) a European multicenter study to unravel the role of IGF-I titrated GH dosing. The timing and regulation of puberty have been

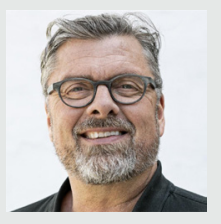
a central research theme, which led to the initiation of the Copenhagen minipuberty study. A recent research interest has been the evaluation of novel biomarkers in DSD conditions, such as Klinefelter syndrome, CAH and PAIS. 
well as females, but with sex-differences in their absolute concentrations and their ratios.

In this review, we will discuss updated knowledge on diagnostic, clinical and therapeutic aspects of disordered sex steroid action in puberty, as well as the impact of altered pubertal timing on disease later in life.

\section{Endocrinology of normal puberty}

Physiological puberty is initiated, when the enhanced pulsatile release of gonadotropin releasing hormone (GnRH) activates the hypothalamic-pituitary-gonadal (HPG) axis. The HPG axis is transiently activated in neonatal development and early infancy (mini puberty) during which gonadotropins and sex hormones rise to a level corresponding to pubertal levels, only to fall after approximately 3 months and stay low until puberty (1). In prepubertal children, there is sex steroid action, but at lower levels than in puberty (2). The onset of puberty in both boys and girls is initiated by the reactivation of the HPG axis. The pulsatile pituitary luteinizing hormone (LH) and follicle stimulating hormone (FSH) release into the systemic circulation stimulates sex steroid production in gonads. In the male child, LH stimulates testicular Leydig cells to release $\mathrm{T}$ as into circulation. $\mathrm{T}$ exerts its actions through the androgen receptor (AR), but is also converted to estradiol by aromatase in fatty tissue and converted to the more potent androgen DHT by 5-alfareductasein androgen -sensitive target organs. In girls, LH stimulates ovarian theca cells to produce testosterone, which is converted by the FSH-induced aromatase in granulosa cells to estradiol that binds to estrogen receptors in estrogen responsive target tissues.

\section{Steroid action throughout life in health and disease}

The HPG axis is active throughout life in females and males with three distinct periods; in fetal life (2ndand 3rdtrimester), in minipuberty and again in puberty and into adulthood. In adult women additional phases, climacteric and postmenopausal periods, follow the reproductive period. In males, testosterone levels are important for androgenization of the male fetus, are involved in testicular descent in late gestation or early postnatal life and virilization of the boy to ensure adult male phenotype. Disorders with altered testosterone secretion may present in fetal or infant life (like CHH, $45, \mathrm{X} / 46, \mathrm{XY}$,
Patterns in Serum Levels in Male Fetuses and Infants

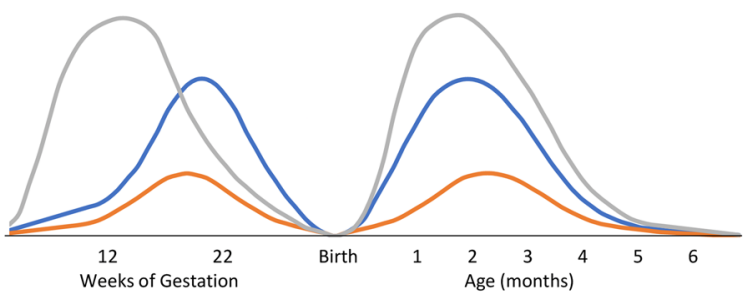

— $\mathrm{LH}-\mathrm{FSH} \longrightarrow$ Testosterone

Patterns in Serum Levels in Female Fetuses and Infants

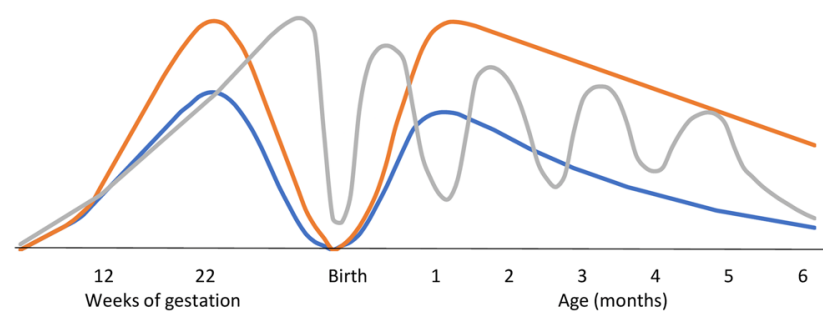

${ }_{\mathrm{LH}}^{\mathrm{LH}} \mathrm{FSH}_{\mathrm{Es} \text { stradiol }}$

Figure 1

Y-axis: serum level of gonadotropins and sex steroid in the healthy fetus and infant. X-axis: gestational age of the fetus, birth, and then chronological age of the infant. Top panel: serum level variation in male fetuses and infants. Bottom panel: serum level variation in female fetuses and infants.

or $47, \mathrm{XXY}$ ) or in conditions with precocious or delayed pubertal onset. The activity of the HPG axis in early life during minipuberty may be an indicator of adult gonadal activity (Fig. 1) (3).

\section{The initiation of puberty}

The reactivation of the HPG axis is the key factor to the onset of pubertal changes in the body. This stimulates the development of secondary sex characteristics and a growth spurt. Traditionally, timing of puberty is considered normal, if pubertal development is initiated between age $8-13$ for girls and $9-14$ for boys $(4,5)$. Additional diagnostic criteria have recently been introduced and classify boys and girls with delayed puberty if the pubertal development falls below 2 s.D. on a standard puberty nomogram for genital or breast development $(6,7)$.

Age at onset of puberty seems to have been declining globally during the last 4 decades (8). Genetic, environmental and nutritional factors are all important factors involved in pubertal timing. 
Hypothalamic neuropeptides influence the timing of puberty. Kisspeptin and neurokinin B are neuropeptides with a stimulatory effect on the timing of puberty, whereas the protein makorin ring finger protein 3 (MKRN3) inhibits puberty. Mutations in the MKRN3 gene are the most frequent known cause of familial central precocious puberty (9).

Although genetics play an important role for pubertal timing, it cannot explain the rapid decline in age at sexual maturation which must be due to changes in environmental and nutritional factors. Especially the increasing obesity rate around the world has been pointed at as a major factor for early puberty. However, obesity did not explain the marked earlier breast development in Denmark, where a study has suggested that endocrine disrupting chemicals are likely to be involved (10).

\section{Development of secondary sex characteristics}

The timing of physical signs of puberty in children was first evaluated by Tanner in 1968, and the Tanner staging for pubic hair, genital and breast development is still used for clinical puberty assessment worldwide (4).

In boys, puberty is initiated by testicular growth, growth of scrotum and penis and pubic hair. Two to three years after puberty initiation, peak height velocity, voice break, and spermarche occur. This continuum is described in five distinct stages for genital development (G1 to G5), and six stages for pubic hair development (PH1 to PH6).

In girls, the physical landmarks of puberty include breast budding and pubic hair development. Girls tend to have growth spurt at an early puberty stage, while menarche is a late pubertal marker. This continuous pubertal development is categorized into five distinct stages for breast development (B1 to B5) and pubic hair development (PH1 to PH5). Thelarche precedes pubarche in most Caucasian girls (thelarche pathway), while AfroAmerican girls tends to enter puberty earlier and more often with pubarche as the first pubertal landmark (pubarche pathway) (11).

\section{Sex steroids and linear growth}

Sex steroid action stimulates linear growth and results in a pubertal growth spurt with a maximal velocity occurring some years after pubertal onset, depending on the sex.

Increasing sex steroid levels stimulate linear growth by direct effects on epiphyseal growth plates, but also indirectly via stimulation of pituitary growth hormone $(\mathrm{GH})$ secretion which in turn stimulates hepatic insulinlike growth factor-I (IGF-I) release.

Thus, sex steroids (primarily estradiol) stimulate linear growth at low concentrations (for review see (12)) but are also responsible for epiphyseal closure and growth cessation at high concentrations. An early puberty results in a high peak height velocity (PHV) (Fig. 2), but also an early epiphyseal closure. Thus, adult height is not much influenced by early or late pubertal timing within the normal range, whereas subjects with rapidly progressing precocious puberty end up considerably shorter than their target height.

Subjects lacking estrogen action due to ER mutation or aromatase deficiency (CYP19 mutation) continue to grow and can end up with gigantism due to the lack of epiphyseal closure (13).

The pubertal sex steroid exposure of the adolescent body results in the marked changes that lead to the normal adult phenotype, depending on type of exposure (estrogens and/or androgens), the level of steroid and the
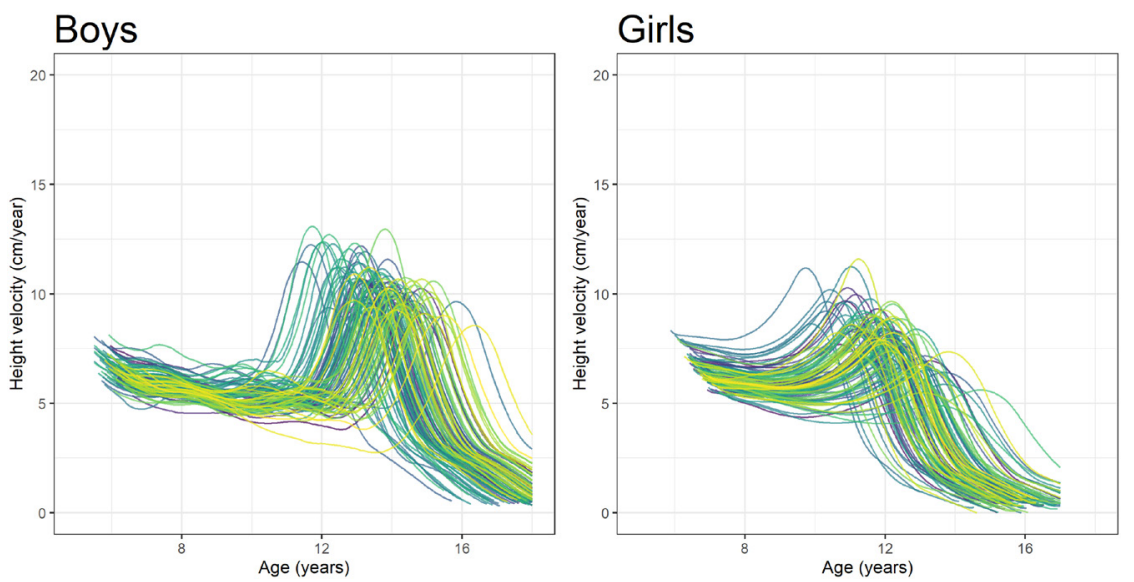

Figure 2

Longitudinal height velocities (cm/year) according to age in boys and girls. Data regarding height velocity curves have previously been presented as raw data $(7,56)$. 
timing of it. Pathological changes in sex steroid exposure and its timing are seen in common pubertal disorders, as well as in rare endocrine disorders. Too early sex steroid action is observed in precocious puberty and its variants. Too late sex steroid action is seen in constitutional delay of growth and puberty (CDGP). Too much sex steroid can result in virilization in girls due to androgen excess (e.g. congenital adrenal hyperplasia (CAH), polycystic ovary syndrome (PCOS)) or feminizaton (gynecomastia) in boys due to estrogen excess (e.g. hCG producing tumors). Too little sex steroid action is seen in children with hypogonadotropic hypogonadism, sex steroid synthesis defects or primary gonadal insufficiency for example, due to Turner syndrome in girls, as well as anorchia or Klinefelter syndrome in boys.

Exogenous sex steroid treatment alters physical appearance and can be used as a tool in reduction of final height in tall stature or be part of deliberate genderaffirming cross hormone therapy in adolescents with gender dysphoria.

\section{Too early puberty}

Precocious puberty (PP) is traditionally defined as clinical signs of puberty before 8 years of age in girls, and before 9 years of age in boys (4). Precocious puberty is more frequent in girls than in boys in ratio 10:1 (14).

The incidence of PP was found to be stable over a period of 8 years (1993 to 2001) in a study from Denmark and corresponded to $0.9-1.3$ new cases per 100000 per year (14). This aligns with a study from France (15), but not with other studies from Spain and South Korea which have shown a ten-fold lower incidence in Spain and a rising incidence in South Korea $(16,17)$. This discrepancy may be caused by several factors. Nutritional alterations may have caused an actual decline in pubertal onset age, but also, increased attention and awareness can be a cause of the increased diagnosing.

Attention should be paid to precocious puberty, since PP untreated can cause shorter final height and is associated with psychological distress, low educational levels and risk-taking behaviors such as alcohol abuse (18, $19,20)$. Early onset of puberty in the general population (and not PP per se) has been found to be associated with obesity, metabolic and cardiovascular risks in some studies, although this field remains to be further elucidated (21).

Precocious puberty can be divided into GnRHdependent (central) or GnRH-independent (peripheral) types.
The most common cause is central precocious puberty (CPP), which is caused by an activation of the hypothalamus and pituitary gland and is recognized by increase in LH and FSH levels and with that, increase in sex steroid serum levels.

More rarely, the cause is independent of GnRH, so-called peripheral precocious puberty (PPP) and is caused by production of supraphysiological sex steroid hormone in endocrine glands or tumors. The patient's blood samples present with high levels of sex steroids but suppressed gonadotropins and no central activation.

Central PP is most often benign and with no organic cause. This is known as idiopathic CPP. CPP can also be caused by underlying brain pathologies like hamartoma, benign or malignant brain tumors.

PPP is observed in diseases like late-onset congenital adrenal hyperplasia, granulosa cell tumors, testotoxicosis or McCune Albright syndrome (MAS) (22).

The reason for referral to PP evaluation is often breast development, growth of pubic and axillary hair and/or rapid growth.

The diagnostic evaluation for PP includes a thorough family history, personal medical history, a physical examination focusing on tanner staging, evaluation of growth, bone age determination and measurement of sex steroids and gonadotropins (4).

The gold standard diagnostic test for PP is the GnRH stimulation test. If peak LH concentration is above $5 \mathrm{IU} / \mathrm{L}$ (or LH/FSH ratio > 0.6) following GnRH stimulation, the diagnosis of CPP is confirmed. Children at the age of 1-3 years will have higher sex hormone serum levels because of the minipuberty, and peak LH should be above $9 \mathrm{IU} / \mathrm{L}$ following a GnRH stimulation test in children this age to confirm a CPP diagnosis $(23,24)$. A GnRH test is not necessary, if basal gonadotropin levels are in pubertal range.

MRI of the brain can be indicated because of the risk of intracranial pathology, but the incidence of pathological findings is low, and MRI of the brain is only indicated in certain high-risk groups.

Groups at risk include patients under the age of 6 , patients with neurological symptoms (especially focal symptoms like bitemporal hemianopsia which raise suspicion of a tumor in the area of the optic chiasma and pituitary gland), patients with rapidly progressing puberty and boys, since the percentage of boys with PP who have abnormal cerebral MRI has been found to be up to $70 \%$ in boys in total in a Korean study (25). Also, the clinician should pay certain attention to patients with café-au-lait spots or a familial history with neurofibromatosis-1 (NF-1), 
since NF-1 can be a cause of intracranial tumors related to CPP (26).

Factors arguing against brain $\mathrm{MR}$ are onset of $\mathrm{PP}$ over the age of 6 years and some ethnic groups who have a tendency toward early normal puberty including internationally adopted children, as patients with such factors are more likely to present with ICPP and no intracranial pathology $(26,27,28)$.

Premature breast or pubic hair development is often due to self-limiting variants like premature thelarche (PT) or premature adrenarche (PA) (29) for which no treatment is indicated. However, clinical follow-up is important for this patient group, since patients with PT or PA have a higher risk of developing CPP later. Sudden development of the larche in the 3-5 years old girl with simultaneous growth acceleration should prompt further investigations to rule out pathology or exogenous sex steroid contamination (30).

Central precocious puberty can be treated with $\mathrm{GnRH}$ agonist (GnRHa) to halt maturation via suppression of the HPG axis. The goals of GnRH agonist treatment are to delay further pubertal development and to ensure the maximum height potential at the given point, since girls with CPP tend to end up with a shorter final height due to early maturation of the bone (12).

GnRHa is effective for final height improvement in girls $<6$ years, but the effect of treatment initiation in girls aged 6-8 years remain uncertain and may have no or limited effect on final height $(22,31)$. There is uncertainty of the increased height potential and the improvement of psychosocial health as a result of the treatment, even though treatment initiation is not uncommon at this age (32). GnRHa treatment might induce a weight gain in the patient, but this concern is not verified (31).

The estimated height gain is dependent on the accuracy of the initial pre-treatment final height prediction based on various prediction models (e.g. Bailey-Pinneau) that are not validated in CPP. GnRHa has been administered as 1- or 3-monthly depot injections, but 6-monthly injections are also being used. One-year subcutaneous implants with GnRHa have also shown adequate suppression (22).

The treatment of PPP depends very much on the cause. Granulosa cell tumors require surgical removal, while late-onset $\mathrm{CAH}$ is a steroid synthesis defect and requires exogenous hydrocortisone treatment. Testotoxicosis and McCune-Albright syndrome have been found to respond to treatment with aromatase inhibitors (22).

\section{Too late sex steroid action}

The disorders causing too late and too little sex steroid action often overlap and they will be mentioned together in the following chapter.

Too late sex steroid action/production presents more often in boys than in girls (33). Delayed puberty may cause lack of virilization/feminization and fertility problems in adulthood and can lead to psychosocial problems and low self-esteem $(5,34)$. Late menarche is related to lower educational level and a lower BMI in adult life $(18,21)$.

In boys, constitutional delay in growth and puberty (CDGP) is a benign common form of delayed puberty (6), but underlying syndromes must be excluded. In contrast, girls who present with delayed puberty should be paid certain attention, as they more often have an underlying pathological condition compared to boys (35).

Congenital hypogonadotropic hypogonadism $(\mathrm{CHH})$ is caused by full or partial malfunction of the HPG axis with or without associated anosmia or hyposmia, due to genetic mutations $(5,34)$. Intracerebral tumors and disorders in the hypothalamic-pituitary area are rare causes of $\mathrm{CHH}$ but the risk of a craniopharyngioma should be considered, since this slow-growing tumor presents with delayed puberty as the first symptoms in up to $19 \%$ of cases (36).

Functional hypogonadotropic hypogonadism (FHH) is a reversible condition and can be caused by nutritional insufficiency, restrictive eating habits, malabsorption or reduced caloric availability as well as excessive exercise. In female adolescents, eating disorders (anorexia, bulimia), eating/training disorders (orthorexia) or elite sports are frequent causes of functional hypothalamic amenorrhea (FHA). It has been hypothesized, that psychosocial stress and worry could trigger FHA through increased levels of cortisol, but the impact of this mechanism is unknown (35).

Hypergonadotropic hypogonadism due to primary gonadal insufficiency is seen in girls with POI, most commonly caused by Turner syndrome, and in boys with Klinefelter syndrome or anorchia. These conditions can present with delayed or lack of puberty, which may lead to the underlying diagnosis $(37,38)$. Hypergonadotropic hypogonadism can also be secondary to gonadotoxic radiotherapy or chemotherapy in females, while males who have undergone iatrogenic gonadotoxic therapy experience low fertility, but normal sex steroid levels (39).

Diagnostic evaluation of delayed puberty: Diagnostic evaluation includes a family history, medical history, 
physical examination, bone age determination, biochemical assays including INSL3, basal FSH and LH concentrations determined by ultrasensitive assays, sex steroid quantification, IGF-I and thyroid-stimulating hormone (TSH) levels.

The clinician should first rule out chronic disease as the cause and then seek to distinguish between $\mathrm{CHH}$ and CDGP. If low gonadotropin levels are found, secondline evaluation may include a GnRH test and/or a hCG stimulation test to determine peak testosterone levels. In some cases, basal measures of $\mathrm{AMH}$ and Inh B (or even the Leydig cell marker INSL3) can replace the more costly hCG test, but the efficiency of this is still discussed (33). If $\mathrm{CHH}$ is found, MRI of the brain and testing of other pituitary hormonal axes must be performed to rule out intracranial pathology (34). Distinguishing between CDGP and $\mathrm{CHH}$ (especially in partial forms) are difficult and often impossible because of the overlapping biochemical markers and a final diagnosis requires watchful waiting (40).

If hypergonadotropic hypogonadism is found, karyotype should be performed to determine any possible chromosome defects (37).

The treatment of delayed puberty will be mentioned in a later chapter under 'puberty induction by sex steroids'.

\section{Too little sex steroid action in adolescence}

In cases of too little sex steroid production, subjects enter puberty at the expected time, but sex hormone levels and action are at subnormal levels.

Too little sex steroid action is seen in patients with rare steroid synthesis defects or with androgen receptor (AR) defects (partial or complete androgen insensitivity syndrome (PAIS or CAIS)). Patients with PAIS raised as males typically present with micropenis, hypospadias and develop gynecomastia due to high E2 and T/E2 imbalance (41). Patients with CAIS virtually always identifies as females, are reared as females and develop female secondary sex characteristics, although their $\mathrm{T}$ and E2 serum levels are in a typical male range (42). Defects in steroid action are also seen in patients with 5-alpha reductase deficiency. This deficiency will prevent the conversion of $\mathrm{T}$ to the much more potent DHT in local, androgen-sensitive tissue and individuals with this disorders often present as 46,XY females (43).

Boys with chromosome disorders like $47, \mathrm{XXY}$ or $45, \mathrm{X} / 46, \mathrm{XY}$ can have varying phenotypes. Some patients are found in childhood because of developmental issues, some are found in adolescence because of a delayed or absent puberty, but most patients are not aware of their condition before they visit the fertility clinic, and most of them never seek medical attention and are never diagnosed. Other patients will, however, experience under masculinization in adolescence $(44,45)$. Girls with Turner (TS) syndrome are characterized by complete or partial (mosaic) lack of one $\mathrm{X}$ chromosomes, causing short stature, hypergonadotropic hypogonadism, absence of puberty and fertility problems in adulthood. Most girls with TS need hormonal replacement therapy to induce puberty and maintain secondary sex characteristics throughout adulthood. Signs of puberty spontaneously occur in $1 / 3$ TS patients, but menstrual cycles are only present in $-6 \%$, most of these with TS mosaicism $(37,46)$.

\section{Puberty induction by sex steroids}

Mimicking normal puberty requires accurate dosage and timing. The challenge of sex steroid treatment is to ensure progression, maximize growth potential and minimize adverse effects at the same time (37). Optimal timing of initiation can minimize negative psychosocial consequences. Treatment for delayed puberty depends on etiology, sex, age and the preference of the patient. CDGP is a condition, in which the patient (in retrospect) has a normal but delayed pubertal growth spurt. The delayed growth and pubertal development can be stimulated with exogenous sex steroid in cases, where the growth is significantly retarded, the bone age is past 10 years, and when there are no imminent clinical or biochemical signs of puberty. Thus, male and female patients can be treated for CDGP with testosterone and estradiol, respectively.

For male patients, several testosterone formulations exist and have been used to in this treatment. These include intramuscular testosterone enanthate (initial dose $50 \mathrm{mg}$ intramuscularly monthly followed by gradual increasing doses), oral testosterone undecanoate (initial dose $40 \mathrm{mg}$ orally daily, increased gradually to $80 \mathrm{mg}$ twice daily), or transdermal testosterone (initial dose 10 mg transdermally every day or every second day hereafter increasing gradually) monitored by clinical signs, bone age, and reproductive hormones (for review see (47)). Treatment with oral testosterone does not appear to compromise final height in boys with $\operatorname{CDGP}(5,6)$.

In hypogonadal girls, puberty induction is done using natural $17 \beta$-estradiol preferably through the transdermal (TD) route. TD treatment is preferred to oral treatment. Estrogen is metabolized in the liver and negative effects of first pass metabolism are avoided when using TD 
treatment (48). For TS patients, the alternative ethinyl estradiol should be avoided because of the hypertensive side effects in this high-risk group (37). Initiation should start at 11-12 years of age, beginning with low dose transdermal treatment (initial dose $6.25 \mu \mathrm{g}$ nocturnal application) with an increasing dose over a period of approximately 2 years reaching adult E2 dose and ageappropriate circulating E2 levels. When break-through bleeding occurs (or maximally 2 years after initiation of therapy) cyclic progestin is added (49).

\section{Too much sex steroid action in adolescence}

This chapter will cover the topics PCOS, late-onset CAH and gynecomastia.

Androgen excess disorders can, in girls, result in hirsutism with 'male' pattern hair growth and acne. In cases with a more pronounced and rapid production of testosterone, virilization occurs with clitoris enlargement and deepening of voice. Hirsutism is the result of an endocrine imbalance, adrenal or ovarian, and a common cause is PCOS (polycystic ovarian syndrome). Excess adrenal androgen production is also seen in late-onset $\mathrm{CAH}$ - an autosomal recessive disease of the adrenal cortex usually caused by mutations in the CYP21A2 gene. Impairment of cortisol biosynthesis due to enzyme deficiency results in high ACTH levels because of negative feedback and the resulting overstimulation of the adrenal gland causes excess androgen production. Rare causes of excessive androgen production are tumors in the ovary (Sertoli-Leydig cells) or in the adrenal gland, causing rapid development of virilization. Hirsutism in adolescent girls often cause psychological distress and social difficulties due to cultural stigmas. The degree, severity and area of distribution of hirsutism is evaluated by FerrimanGallwayscore - published in 1961 and further modified in 2001 (50).

Diagnosing PCOS during adolescence is challenging because features of normal pubertal development overlap with diagnostic criteria. Criteria to improve diagnostic accuracy and avoid over-diagnosis in adolescents include (i) irregular cycles defined according to years since menarche and (ii) hyperandrogenism defined as hirsutism, acne and/or hyperandrogenemia confirmed using validated high-quality assays. However, pelvic ultrasound and antimüllerian hormone (AMH) levels are not recommended for the diagnosis of PCOS within 8 years post menarche. Disorders that mimic PCOS should be excluded (51). For management of symptoms in PCOS, the combined oral contraceptive pill that contains estrogen and progestin, is effective and lowers the ovarian production of testosterone as well as it increases the liver secretion of sex hormone binding globulin (SHBG) and thereby reduces the levels of free $\mathrm{T}$. In adolescents insulin sensitizers such as metformin are beneficial and a treatment of the metabolic disorder considered to be part of the mechanism of action. Metformin can induce a small weight loss in the overweight patient (51). Antiandrogens (finasteride or spironolactone) possibly combined with $\mathrm{OCP}$, have been found to be more effective than insulin sensitizers on hirsutism. The possible teratogenic effect of this drug should be discussed with the young female patient, who should avoid pregnancy during the treatment. Available data endorse the benefits of healthy lifestyle interventions to prevent weight gain and should be recommended (52).

In the case of late-onset CAH, hyperandrogenism is caused by androgen production in the adrenal gland but does - in contrast to classical CAH - not have clinical manifestations until after infancy up to early adulthood and does usually not induce adrenal insufficiency.

The treatment for $\mathrm{CAH}$ is glucocorticoid supplementation, but for the adolescent person with lateonset $\mathrm{CAH}$, glucocorticoids are only indicated in cases of severe hyperandrogenism, physical stressor adrenal insufficiency (53). Attention to glucocorticoid treatment should be paid, because excess levels can result in obesity, growth suppression and decreased bone mineral density. In contrast, absence of adequate androgen suppression can lead to early puberty, virilization, adrenal rest tumor formation and adverse psychological effects, which is why these patients should be followed closely (53).

Rare causes of hyperandrogenism are androgen producing tumors in the ovary (Sertoli-Leydig cells) or adrenal gland, often causing rapid development of virilization. Androgen producing tumors are treated with surgery.

Gynecomastia is the inappropriate appearance of glandular breast tissue. Gynecomastia is normally observed in pubertal boys, but prepubertal gynecomastia is rarely observed and is often a symptom in Sertoli cell tumors in boys with Carney syndrome or Peutz-Jeghers syndrome (54). This should be distinguished from lipomastia (also called pseudo-gynecomastia) by thorough palpation. Gynecomastiais caused by an imbalance in the androgen/ estrogen ratio. This can be caused by lowered androgen levels or by elevated estrogen levels, since androgens inhibit breast tissue proliferation via AR and estrogens enhance proliferation via ER (55). Transient gynecomastia is a physiological phenomenon in mid-pubertal boys 
(genital stages 3-4) and is seen in up to $50 \%$ of boys but will disappear within 6-24 months (56). Persistent pubertal gynecomastia can be a sign of decreased levels of androgens as seen in Klinefelter syndrome, or due to defective androgen receptor signaling as seen in boys with PAIS (41). If the patient is otherwise healthy, the clinician might want to ask the patient about the use of lavender oil, which is linked to prepubertal gynecomastia (57).

\section{Timing is everything}

Early sex steroid action resulting in precocious puberty has long-term health consequences as we have covered in this review $(58,59)$.

Late sex steroid action resulting in delayed puberty has long-lasting consequences for bone health. Thus, Finkelstein et al. have shown that men with a history of delayed puberty have increased risk of osteopenia (60). In addition, recent epidemiological evidence find that late puberty is associated with increased risk of asthma, eczema, inflammatory bowel disease and psychiatric comorbidities (bipolar diseases, chronic fatigue syndrome, depression) (61). Timing of sex steroid action is key. Early and late puberty timing in both women and men are associated with higher risks of adverse outcomes, across a range of cancers, cardio-metabolic, gynecological/obstetric, gastrointestinal, musculoskeletal, and neuro-cognitive categories, although chronic disease may sometimes be the actual cause of delayed puberty (61) (Fig. 3).

\section{Treatment with exogenous administration of high-dose sex steroids in tall statured children}

Tall stature may be caused by several syndromes like Marfansyndrome, Sotossyndrome, Fragile X syndrome, Beckwith-Wiedemann syndrome, homocystinuria or sex chromosome anomalies (47,XXY, 47,XYY, 47,XXX) which need to be ruled out first. Idiopathic (familial) tall stature is not a pathological condition per se and does not need treatment. Idiopathic (familial) tall stature is not a pathological condition and does not need hormonal treatment. Adolescents with extreme final height predictions and their families should be counselled on potential options. Today, surgical treatment with percutaneous epiphysiodesis is preferred for patients with a bone age less than 12.5 years in girls and 14 years in boys. The other option, sex steroid

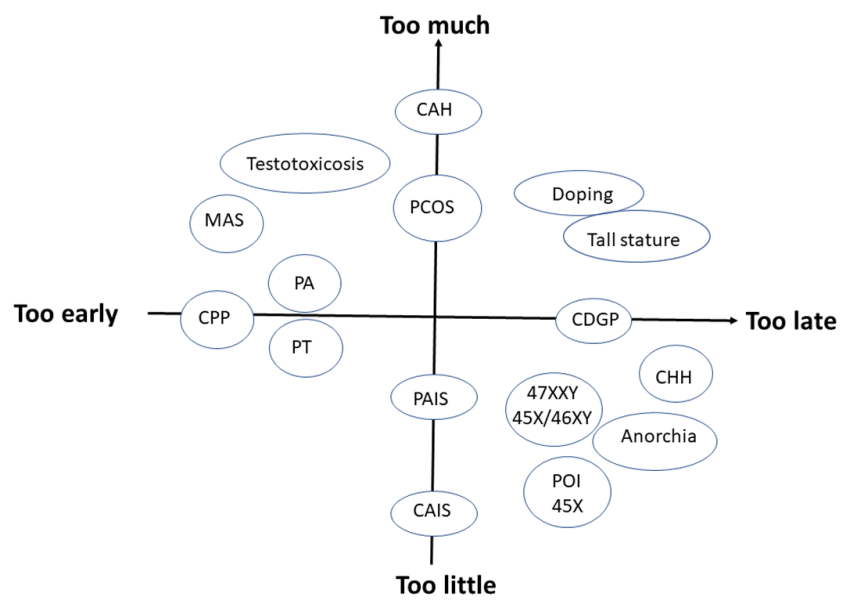

Figure 3

Sex steroid action in puberty in children and adolescents with rare endocrine disorders. Too early sex steroid activity is observed is central precocious puberty (CPP), premature thelarche (PT), premature adrenarche (PA), McCune Albright syndrome (MAS) and testotoxicosis. Too late sex steroid action is observed in patients with constitutional delay in growth and puberty (CDGP) and congenital hypogonadotropic hypogonadism. Too much sex steroid activity is observed in patients with congenital adrenal hyperplasia (CAH), polycystic ovary syndrome (PCOS), or patients treated with sex steroids due to tall stature, or misuse of anabolic androgenic substances (doping). Too little sex steroid action is observed in patients with partial androgen insensitivity syndrome (PAIS), complete androgen insensitivity (CAIS), premature ovarian insufficiency (POI) and Turner syndrome $(45, X)$, Klinefelter syndrome $(47, X X Y)$ and mixed gonadal dysgenesis $(45, X / 46, X Y)$.

treatment, is seldomly used nowadays. The moderate height reduction, risk of impaired fertility in women and melanomas argue against routine use of high-dose sex steroids in adolescents with idiopathic tall stature (62, $63,64)$. In the exceptions where treatment is initiated, high-dose ethinyl estradiol or natural estradiol is used to ensure an early and rapidly progressing puberty (65). Tall statured boys have been given very high testosterone doses (testosterone enanthate 250-500 mg every 2 weeks (66)) with significant reduction in final height if treatment is initiated early. Importantly, severe long-term consequences to pharmacological intervention exist. Thus, high-dose estrogen-treated tall women are at risk of subfertility in later life and show signs of accelerated ovarian aging with concomitant follicle pool $(64,67)$. By contrast, fatherhood and semen quality in tall men treated with testosterone in adolescence have, in newer studies, been found not be affected $(68,69)$. 


\section{Transgender youth}

A transgender person experiences in congruence between the natal (assigned) sex and the perceived gender identity, which in consequence can lead to gender dysphoria (GD). The onset of GD may be in childhood and can reach into adolescence or adulthood but desist in the majority (70). Often, GD becomes more severe with onset of secondary sex characteristics during puberty. Epidemiological reviews have shown a high prevalence of mental disorders, psychological distress and social marginalization in this group (71). The prevalence is unknown but appears to be increasing in most countries, especially amongst natal girls. The etiology is unknown, but biological and societal factors are discussed, and the origin of GD may be multifaceted.

Standards of care for children and adolescents are based on a team of psychologists, psychiatrists and endocrinologists in the assessment and treatment of GD (71). Endocrine treatment consists of puberty suppression with GnRHa and gender-affirming treatment with sex hormones. Puberty suppression from Tanner stage 2 diminishes the discordance between body appearance and gender identity and thus creates a time window for gender clarification before irreversible cross sex hormone treatment is initiated. Long acting GnRHa stops development of breast tissue and menstruations in girls and stops testis growth and virilization in boys. Sex hormone treatment is often initiated around age 15-16 years (72), testosterone in female-to-male and estradiol in male-tofemale and continued lifelong. Fertility preservation with semen or ovarian cryopreservation prior to hormone treatment is possible, but not routinely established yet in all countries- or even legal $(73,74)$. Despite the existence of treatment options for more than 20 years and relatively homogeneous clinical guidelines world-wide, little longterm data are available on the safety of treatment and randomized clinical trials of different treatment regimens are lacking (75).

\section{Concluding remarks}

Changes in sex steroid levels in the pubertal transition result in changes in body and mind. Puberty is recognized as a period of emotional instability, vulnerability, immature decision making, as well as growth acceleration, development of secondary sex characteristics, psychomotor adjustments, and a transient 'acromegalic state' with associated insulin resistance.
Abnormal development or timing may worsen all these signs and symptoms. Adolescents with chronic diseases face these changes of puberty like other teenagers but may be additionally challenged by their disease which may interfere with the pubertal changes. This requires careful considerations, and expertise by health care providers who manage chronic patients in the transitional period. The European reference network for rare endocrine disorders (ENDO_ERN) encompasses perspectives from endocrine patients, pediatric as well as adult (www.endo-ern.eu). There is a focus within ENDO-ERN to ensure optimal transition through pubertal transition for patients with endocrine disorders.

\section{Declaration of interest}

The authors declare that there is no conflict of interest that could be perceived as prejudicing the impartiality of this review.

\section{Funding}

This research did not receive any specific grant from any funding agency in the public, commercial or not-for-profit sector.

\section{References}

1 Johannsen TH, Main KM, Ljubicic ML, Jensen TK, Andersen HR, Andersen MS, Petersen JH, Andersson AM \& Juul A. Sex differences in reproductive hormones during mini-puberty in infants with normal and disordered sex development. Journal of Clinical Endocrinology and Metabolism 2018103 3028-3037. (https://doi.org/10.1210/jc.201800482)

2 Frederiksen H, Johannsen TH, Andersen SE, Albrethsen J, Landersoe SK, Petersen JH, Andersen AN, Vestergaard ET, Schorring ME, Linneberg A et al. Sex-specific estrogen levels and reference intervals from infancy to late adulthood determined by LC-MS/MS. Journal of Clinical Endocrinology and Metabolism 2020105 754-768. (https://doi.org/10.1210/clinem/dgz196)

3 Renault CH, Aksglaede L, Wojdemann D, Hansen AB, Jensen RB \& Juul A. Minipuberty of human infancy - a window of opportunity to evaluate hypogonadism and differences of sex development? Annals of Pediatric Endocrinology and Metabolism 202025 84-91. (https://doi. org/10.6065/apem.2040094.047)

4 Carel JC \& Léger J. Clinical practice. Precocious puberty. New England Journal of Medicine 2008358 2366-2377. (https://doi.org/10.1056/ NEJMcp0800459)

5 Palmert MR \& Dunkel L. Clinical practice. Delayed puberty. New England Journal of Medicine 2012366 443-453. (https://doi. org/10.1056/NEJMcp1109290)

6 Lawaetz JG, Hagen CP, Mieritz MG, Jensen MB, Petersen JH \& Juul A. Evaluation of 451 Danish boys with delayed puberty: diagnostic use of a new puberty nomogram and effects of oral testosterone therapy. Journal of Clinical Endocrinology and Metabolism 2015100 1376-1385. (https://doi.org/10.1210/jc.2014-3631)

7 Lindhardt Johansen M, Hagen CP, Mieritz MG, Wolthers OD, Heuck C, Petersen JH \& Juul A. Pubertal progression and reproductive hormones in healthy girls With transient thelarche. Journal of Clinical Endocrinology and Metabolism 2017102 1001-1008. (https://doi. org/10.1210/jc.2016-2871) 
8 Eckert-lind C, Busch AS, Petersen JH, Biro FM, Butler G, Bräuner E $\mathrm{v} \&$ Juul A. Worldwide secular trends in age at pubertal onset assessed by breast development among girls: a systematic review and meta-analysis. JAMA Pediatrics 2020174 e195881. (https://doi. org/10.1001/jamapediatrics.2019.5881)

9 Abreu AP \& Kaiser UB. Pubertal development and regulation. Lancet: Diabetes and Endocrinology 20164 254-264. (https://doi.org/10.1016/ S2213-8587(15)00418-0)

10 Aksglaede L, Sørensen K, Petersen JH, Skakkebæk NE \& Juul A. Recent decline in age at breast development: the Copenhagen puberty study. Pediatrics 2009123 e932-e939. (https://doi.org/10.1542/peds.20082491)

11 Biro FM, Huang B, Daniels SR \& Lucky AW. Pubarche as well as thelarche may be a marker for the onset of puberty. Journal of Pediatric and Adolescent Gynecology 200821 323-328. (https://doi. org/10.1016/j.jpag.2007.09.008)

12 Juul A. The effects of oestrogens on linear bone growth. Human Reproduction Update 20017 303-313. (https://doi.org/10.1093/ humupd/7.3.303)

13 Smith EP, Boyd J, Frank GR, Takahashi H, Cohen RM, Specker B, Williams TC, Lubahn DB \& Korach KS. Estrogen resistance caused by a mutation in the estrogen-receptor gene in a man. New England Journal of Medicine 1994331 1056-1061. (https://doi.org/10.1056/ NEJM199410203311604)

14 Teilmann G, Pedersen CB, Jensen TK, Skakkebæk NE \& Juul A. Prevalence and incidence of precocious pubertal development in Denmark: an epidemiologic study based on national registries. Pediatrics 2005116 1323-1328. (https://doi.org/10.1542/peds.20050012)

15 Moal J le, Rigou A, Tertre A le, Crouy-Channel P de, Léger J \& Carel JC. Marked geographic patterns in the incidence of idiopathic central precocious puberty: a nationwide study in France. European Journal of Endocrinology $2018 \mathbf{1 7 8} 33-41$. (https://doi.org/10.1530/ EJE-17-0379)

16 Soriano-Guillén L, Corripio R, Labarta JI, Cañete R, Castro-Feijóo L, Espino R \& Argente J. Central precocious puberty in children living in Spain: incidence, prevalence, and influence of adoption and immigration. Journal of Clinical Endocrinology and Metabolism 201095 4305-4313. (https://doi.org/10.1210/jc.2010-1025)

17 Kim SH, Huh K, Won S, Lee KW \& Park MJ. A significant increase in the incidence of central precocious puberty among Korean girls from 2004 to 2010. PLOS ONE 201510 e0141844. (https://doi.org/10.1371/ journal.pone.0141844)

18 Calthorpe LM, Gigante DP, Horta BL \& Ong KK. Age at menarche associated with subsequent educational attainment and risk-taking behaviours: the Pelotas 1982 Birth Cohort. Annals of Human Biology 202047 18-24. (https://doi.org/10.1080/03014460.2020.1715476)

19 Costello EJ, Sung M, Worthman C \& Angold A. Pubertal maturation and the development of alcohol use and abuse. Drug and Alcohol Dependence 200788 (Supplement 1) S50-S59. (https://doi. org/10.1016/j.drugalcdep.2006.12.009)

20 Williams VSL, Soliman AM, Barrett AM \& Klein KO. Review and evaluation of patient-centered psychosocial assessments for children with central precocious puberty or early puberty. Journal of Pediatric Endocrinology and Metabolism 201831 485-495. (https://doi. org/10.1515/jpem-2017-0465)

21 Prentice P \& Viner RM. Pubertal timing and adult obesity and cardiometabolic risk in women and men: a systematic review and meta-analysis. International Journal of Obesity 201337 1036-1043. (https://doi.org/10.1038/ijo.2012.177)

22 Fuqua JS. Treatment and outcomes of precocious puberty: an update. Journal of Clinical Endocrinology and Metabolism 201398 2198-2207. (https://doi.org/10.1210/jc.2013-1024)

23 Vestergaard ET, Schjørring ME, Kamperis K, Petersen KK, Rittig S, Juul A, Kristensen K \& Birkebæk NH. The follicle-stimulating hormone (FSH) and luteinizing hormone $(\mathrm{LH})$ response to a gonadotropin-releasing hormone analogue test in healthy prepubertal girls aged 10 months to 6 years. European Journal of Endocrinology 2017 176 747-753. (https://doi.org/10.1530/EJE-17-0042)

24 Seymen Karabulut G, Atar M, Çizmecioglu Jones FM \& Hatun Ş. Girls with premature thelarche younger than 3 years of age might have stimulated LH greater than 10 IU/L. Journal of Clinical Research in Pediatric Endocrinology 20200 0-0. (https://doi.org/10.4274/jcrpe. galenos.2020.2019.0202)

25 Choi KH, Chung SJ, Kang MJ, Yoon JY, Lee JE, Lee YA, Shin CH \& Yang SW. Boys with precocious or early puberty: incidence of pathological brain magnetic resonance imaging findings and factors related to newly developed brain lesions. Annals of Pediatric Endocrinology and Metabolism 201318 183-190. (https://doi. org/10.6065/apem.2013.18.4.183)

26 Mogensen SS, Aksglaede L, Mouritsen A, Sørensen K, Main KM, Gideon P \& Juul A. Pathological and incidental findings on brain MRI in a single-center study of 229 consecutive girls with early or precocious puberty. PLOS ONE 20127 e29829. (https://doi. org/10.1371/journal.pone.0029829)

27 Pedicelli S, Alessio P, Scirè G, Cappa M \& Cianfarani S. Routine screening by brain magnetic resonance imaging is not indicated in every girl with onset of puberty between the ages of 6 and 8 years. Journal of Clinical Endocrinology and Metabolism 201499 4455-4461. (https://doi.org/10.1210/jc.2014-2702)

28 Chiu CF, Wang CJ, Chen YP \& Lo FS. Pathological and incidental findings in 403 Taiwanese girls with central precocious puberty at initial diagnosis. Frontiers in Endocrinology 202011 256. (https://doi org/10.3389/fendo.2020.00256)

29 Mogensen SS, Aksglaede L, Mouritsen A, Sørensen K, Main KM, Gideon P \& Juul A. Diagnostic work-up of 449 consecutive girls who were referred to be evaluated for precocious puberty. Journal of Clinical Endocrinology and Metabolism 201196 1393-1401. (https:// doi.org/10.1210/jc.2010-2745)

30 Vries L de, Guz-Mark A, Lazar L, Reches A \& Phillip M. Premature thelarche: age at presentation affects clinical course but not clinical characteristics or risk to progress to precocious puberty. Journal of Pediatrics 2010156 466-471. (https://doi.org/10.1016/j. jpeds.2009.09.071)

31 Carel JC, Eugster EA, Rogol A, Ghizzoni L, Palmert MR, ESPELWPES GnRH Analogs Consensus Conference Group, Antoniazzi F, Berenbaum S, Bourguignon JP, Chrousos GP et al. Consensus statement on the use of gonadotropin-releasing hormone analogs in children. Pediatrics 2009123 e752-e762. (https://doi.org/10.1542/ peds.2008-1783)

32 Kaplowitz PB, Backeljauw PF \& Allen DB. Toward more targeted and cost-effective gonadotropin-releasing hormone analog treatment in girls with central precocious puberty. Hormone Research in Paediatrics 201890 1-7. (https://doi.org/10.1159/000491103)

33 Raivio T \& Miettinen PJ. Constitutional delay of puberty versus congenital hypogonadotropic hypogonadism: genetics, management and updates. Best Practice and Research: Clinical Endocrinology and Metabolism 201933 101316. (https://doi.org/10.1016/j. beem.2019.101316)

34 Boehm U, Bouloux PM, Dattani MT, Roux N de, Dodé C, Dunkel L, Dwyer AA, Giacobini P, Hardelin JP, Juul A et al. Expert consensus document: European Consensus Statement on congenital hypogonadotropic hypogonadism-pathogenesis, diagnosis and treatment. Nature Reviews: Endocrinology 201511 547-564. (https:// doi.org/10.1038/nrendo.2015.112)

35 Gordon CM, Ackerman KE, Berga SL, Kaplan JR, Mastorakos G, Misra M, Murad MH, Santoro NF \& Warren MP. Functional hypothalamic amenorrhea: an endocrine society clinical practice guideline. Journal of Clinical Endocrinology and Metabolism $2017 \mathbf{1 0 2}$ 1413-1439. (https://doi.org/10.1210/jc.2017-00131)

36 de Vries L, Lazar L \& Phillip M. Craniopharyngioma: presentation and endocrine sequelae in 36 children. Journal of Pediatric 
Endocrinology and Metabolism 200316 703-710. (https://doi. org/10.1515/JPEM.2003.16.5.703)

37 Gravholt CH, Andersen NH, Conway GS, Dekkers OM, Geffner ME, Klein KO, Lin AE, Mauras N, Quigley CA, Rubin K et al. Clinical practice guidelines for the care of girls and women with Turner syndrome: proceedings from the 2016 Cincinnati International Turner Syndrome Meeting. European Journal of Endocrinology 2017 177 G1-G70. (https://doi.org/10.1530/EJE-17-0430)

38 Lanfranco F, Kamischke A, Zitzmann M \& Nieschlag E. Klinefelter's syndrome. Lancet 2004364 273-283. (https://doi.org/10.1016/ S0140-6736(04)16678-6)

39 Wei C \& Crowne E. The impact of childhood cancer and its treatment on puberty and subsequent hypothalamic pituitary and gonadal function, in both boys and girls. Best Practice and Research: Clinical Endocrinology and Metabolism 201933 101291. (https://doi. org/10.1016/j.beem.2019.101291)

40 Rohayem J, Nieschlag E, Kliesch S, Zitzmann M. Inhibin B, AMH, but not INSL3, IGF1 or DHEAS support differentiation between constitutional delay of growth and puberty and hypogonadotropic hypogonadism. Andrology 20153 882-887. (https://doi.org/10.1111/ andr.12088)

41 Hellmann P, Christiansen P, Johannsen TH, Main KM, Duno M \& Juul A. Male patients with partial androgen insensitivity syndrome: a longitudinal follow-up of growth, reproductive hormones and the development of gynaecomastia. Archives of Disease in Childhood 2012 97 403-409. (https://doi.org/10.1136/archdischild-2011-300584)

42 Doehnert U, Bertelloni S, Werner R, Dati E \& Hiort O. Characteristic features of reproductive hormone profiles in late adolescent and adult females with complete androgen insensitivity syndrome. Sexual Development 20159 69-74. (https://doi.org/10.1159/000371464)

43 Cheon CK. Practical approach to steroid 5alpha-reductase type 2 deficiency. European Journal of Pediatrics 2011170 1-8. (https://doi. org/10.1007/s00431-010-1189-4)

44 Ljubicic ML, Jørgensen A, Acerini C, Andrade J, Balsamo A, Bertelloni S, Cools M, Cuccaro RT, Darendeliler F, Flück CE et al. Clinical but not histological outcomes in males with $45, \mathrm{X} / 46, \mathrm{XY}$ mosaicism vary depending on reason for diagnosis. Journal of Clinical Endocrinology and Metabolism 2019104 4366-4381. (https://doi. org/10.1210/jc.2018-02752)

45 Aksglæde L, Skakkebæk NE, Almstrup K \& Juul A. Clinical and biological parameters in 166 boys, adolescents and adults with nonmosaic Klinefelter syndrome: a Copenhagen experience. Acta Paediatrica 2011100 793-806. (https://doi.org/10.1111/j.16512227.2011.02246.x)

46 Klein KO, Rosenfield RL, Santen RJ, Gawlik AM, Backeljauw PF, Gravholt CH, Sas TCJ \& Mauras N. Estrogen replacement in Turner syndrome: literature review and practical considerations. Journal of Clinical Endocrinology and Metabolism 2018103 1790-1803. (https:// doi.org/10.1210/jc.2017-02183)

47 Stancampiano MR, Lucas-Herald AK, Russo G, Rogol AD \& Ahmed SF. Testosterone therapy in adolescent boys: the need for a structured approach. Hormone Research in Paediatrics 201992 215-228. (https:// doi.org/10.1159/000504670)

48 Donaldson M, Kriström B, Ankarberg-Lindgren C, Verlinde S, van Alfen-van der Velden J, Gawlik A, van Gelder MMHJ, Sas T \& on behalf of the European Society for Paediatric Endocrinology Turner Syndrome Working Group. Optimal pubertal induction in girls with Turner syndrome using either oral or transdermal estradiol: a proposed modern strategy. Hormone Research in Paediatrics 201991 153-163. (https://doi.org/10.1159/000500050)

49 Ankarberg-Lindgren C, Elfving M, Wikland KA \& Norjavaara E. Nocturnal application of transdermal estradiol patches produces levels of estradiol that mimic those seen at the onset of spontaneous puberty in Girls1. Journal of Clinical Endocrinology and Metabolism 200186 3039-3044. (https://doi.org/10.1210/ jcem.86.7.7667)
50 Goodman NF, Bledsoe MB, Cobin RH, Futterweit W, Goldzieher JW, Petak SM, Smith KD, Steinberger E \& American Association of Clinical Endocrinologists Hyperandrogenic Disorders Task Force. American Association of Clinical Endocrinologists Medical Guidelines for the clinical practice for the diagnosis and treatment of hyperandrogenic disorders. Endocrine Practice 20017 120-134. (https://doi.org/10.4158/EP.7.2.120)

51 Peña AS, Witchel SF, Hoeger KM, Oberfield SE, Vogiatzi MG, Misso M, Garad R, Dabadghao P \& Teede H. Adolescent polycystic ovary syndrome according to the international evidence-based guideline. BMC Medicine 202018 72. (https://doi.org/10.1186/s12916-02001516-x)

52 Barrionuevo P, Nabhan M, Altayar O, Wang Z, Erwin PJ, Asi N, Martin KA \& Murad MH. Treatment options for hirsutism: a systematic review and network meta-analysis. Journal of Clinical Endocrinology and Metabolism 2018103 1258-1264. (https://doi. org/10.1210/jc.2017-02052)

53 Carmina E, Dewailly D, Escobar-Morreale HF, Kelestimur F, Moran C, Oberfield S, Witchel SF \& Azziz R. Non-classic congenital adrenal hyperplasia due to 21-hydroxylase deficiency revisited: an update with a special focus on adolescent and adult women. Human Reproduction Update 201723 580-599. (https://doi.org/10.1093/humupd/dmx014)

54 Crocker MK, Gourgari E, Lodish M \& Stratakis CA. Use of aromatase inhibitors in large cell calcifying Sertoli cell tumors: effects on gynecomastia, growth velocity, and bone age. Journal of Clinical Endocrinology and Metabolism 201499 E2673-E2680. (https://doi. org/10.1210/jc.2014-2530)

55 Braunstein GD. Clinical practice. Gynecomastia. New England Journal of Medicine 2007357 1229-1237. (https://doi.org/10.1056/ NEJMcp070677)

56 Mieritz MG, Rakêt LL, Hagen CP, Nielsen JE, Talman MLM, Petersen JH, Sommer SH, Main KM, Jørgensen N \& Juul A. A longitudinal study of growth, sex steroids, and IGF-1 in boys with physiological gynecomastia. Journal of Clinical Endocrinology and Metabolism 2015100 3752-3759. (https://doi.org/10.1210/jc.20152836)

57 Ramsey JT, Li Y, Arao Y, Naidu A, Coons LA, Diaz A \& Korach KS. Lavender products associated with premature thelarche and prepubertal gynecomastia: case reports and endocrine-disrupting chemical activities. Journal of Clinical Endocrinology and Metabolism 2019104 5393-5405. (https://doi.org/10.1210/jc.2018-01880)

58 Day FR, Thompson DJ, Helgason H, Chasman DI, Finucane H, Sulem P, Ruth KS, Whalen S, Sarkar AK, Albrecht E et al. Genomic analyses identify hundreds of variants associated with age at menarche and support a role for puberty timing in cancer risk. Nature Genetics 201749 834-841. (https://doi.org/10.1038/ng.3841)

59 Charalampopoulos D, McLoughlin A, Elks CE \& Ong KK. Age at menarche and risks of all-cause and cardiovascular death: a systematic review and meta-analysis. American Journal of Epidemiology 2014180 29-40. (https://doi.org/10.1093/aje/kwu113)

60 Finkelstein JS, Neer RM, Biller BMK, Crawford JD \& Klibanski A. Osteopenia in men with a history of delayed puberty. New England Journal of Medicine 1992326 600-604. (https://doi.org/10.1056/ NEJM199202273260904)

61 Day FR, Elks CE, Murray A, Ong KK \& Perry JRB. Puberty timing associated with diabetes, cardiovascular disease and also diverse health outcomes in men and women: the UK Biobank study. Scientific Reports 20155 11208. (https://doi.org/10.1038/srep11208)

62 Hannema SE \& Sävendahl L. The evaluation and management of tall stature. Hormone Research in Paediatrics 201685 347-352. (https:// doi.org/10.1159/000443685)

63 Benyi E, Kieler H, Linder M, Ritzén M, Carlstedt-Duke J, Tuvemo T, Westphal O \& Sävendahl L. Risks of malignant and non-malignant tumours in tall women treated with high-dose oestrogen during adolescence. Hormone Research in Paediatrics 201482 89-96. (https:// doi.org/10.1159/000360137) 
64 Venn A, Bruinsma F, Werther G, Pyett P, Baird D, Jones P, Rayner J \& Lumley J. Oestrogen treatment to reduce the adult height of tall girls: long-term effects on fertility. Lancet 2004364 1513-1518. (https:// doi.org/10.1016/S0140-6736(04)17274-7)

65 Upners EN \& Juul A. Evaluation and phenotypic characteristics of 293 Danish girls with tall stature: effects of oral administration of natural 17 $\beta$-estradiol. Pediatric Research 201680 693-701. (https:// doi.org/10.1038/pr.2016.128)

66 Reinehr T, Gueldensupp M, Wunsch R \& Bramswig JH. Treatment of tall stature in boys: comparison of two different treatment regimens. Hormone Research in Paediatrics 201176 343-347. (https://doi. org/10.1159/000332735)

67 Hendriks AEJ, Laven JSE, Valkenburg O, Fong SL, Fauser BCJM, Ridder MAJ de, Jong FH de, Visser JA, Ginneken AM van, Boot AM et al. Fertility and ovarian function in high-dose estrogen-treated tall women. Journal of Clinical Endocrinology and Metabolism 201196 1098-1105. (https://doi.org/10.1210/jc.2010-2244)

68 Lemcke B, Zentgraf J, Behre HM, Kliesch S, Bramswig JH \& Nieschlag E. Long-term effects on testicular function of highdose testosterone treatment for excessively tall stature. Journal of Clinical Endocrinology and Metabolism 199681 296-301. (https://doi. org/10.1210/jcem.81.1.8550767)

69 Hendriks AEJ, Boellaard WPA, Casteren NJ van, Romijn JC, Jong FH de, Boot AM \& Drop SLS. Fatherhood in tall men treated with highdose sex steroids during adolescence. Journal of Clinical Endocrinology and Metabolism 201095 5233-5240. (https://doi.org/10.1210/ jc.2010-0435)
70 Steensma TD, McGuire JK, Kreukels BPC, Beekman AJ \& CohenKettenis PT. Factors associated with desistence and persistence of childhood gender dysphoria: a quantitative follow-up study. Journal of the American Academy of Child and Adolescent Psychiatry 201352 582-590. (https://doi.org/10.1016/j.jaac.2013.03.016)

71 Hembree WC, Cohen-Kettenis PT, Gooren L, Hannema SE, Meyer WJ, Murad MH, Rosenthal SM, Safer JD, Tangpricha V \& T'Sjoen GG. Endocrine treatment of gender-dysphoric/gender-incongruent persons: an Endocrine Society* clinical practice guideline. Journal of Clinical Endocrinology and Metabolism 2017102 3869-3903. (https:// doi.org/10.1210/jc.2017-01658)

72 Skordis N, Butler G, Vries MC de, Main K \& Hannema SE. ESPE and PES international survey of centers and clinicians delivering specialist care for children and adolescents with gender dysphoria. Hormone Research in Paediatrics 201890 326-331. (https://doi. org/10.1159/000496115)

73 Nolan IT, Dy GW \& Levitt N. Considerations in gender-affirming surgery: demographic trends. Urologic Clinics of North America 2019 46 459-465. (https://doi.org/10.1016/j.ucl.2019.07.004)

74 Nahata L, Chen D, Moravek MB, Quinn GP, Sutter ME, Taylor J, Tishelman AC \& Gomez-Lobo V. Understudied and underreported: fertility issues in transgender youth - a narrative review. Journal of Pediatrics 2019205 265-271. (https://doi.org/10.1016/j. jpeds.2018.09.009)

75 T'Sjoen G, Arcelus J, Gooren L, Klink DT \& Tangpricha V. Endocrinology of transgender medicine. Endocrine Reviews 201940 97-117. (https://doi.org/10.1210/er.2018-00011)

Received 21 May 2020

Revised version received 30 September 2020

Accepted 14 October 2020 